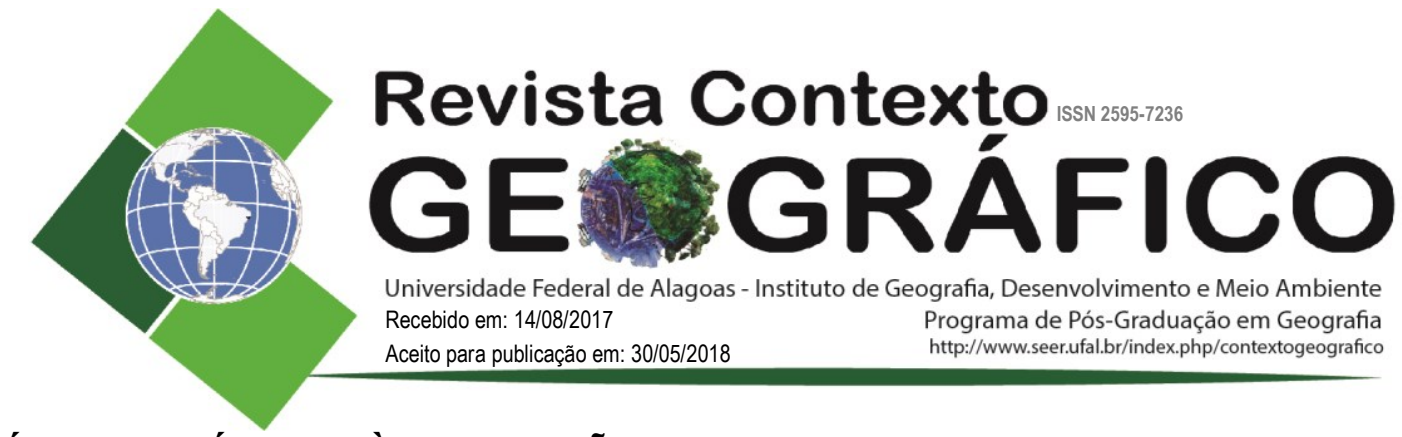

\title{
ÁREAS CRÍTICAS À OCUPAÇÃO URBANA SUJEITAS A DESLIZAMENTO DE TERRA NA BACIA HIDROGRÁFICA DO RIACHO REGINALDO, MACEIÓ-AL
}

\author{
Esdras de Lima Andrade \\ Universidade Federal de Alagoas, Instituto de Geografia, Desenvolvimento e Meio Ambiente, \\ Maceió, AL, Brasil \\ esdras.andrade@,igdema.ufal.br
}

Silvana Quintella Cavalcanti Calheiros

Universidade Federal de Alagoas, Instituto de Geografia, Desenvolvimento e Meio Ambiente,

Maceió, AL, Brasil

qsilvana@uol.com.br

Daniel Nivaldo da Conceição

Instituto do Meio Ambiente de Alagoas, Maceió, AL, Brasil

danieldaconceicao01@gmail.com

\begin{abstract}
RESUMO - A presença humana nas encostas dos tabuleiros costeiros vem transformando consideravelmente este meio, prestes a se colocar em situação de vulnerabilidade frente aos fatores naturais, como as chuvas e aos fatores antrópicos promovidos por sua influência, a exemplo do lançamento de efluentes à céu aberto. Vislumbrando esse cenário, o presente trabalho tem por objetivo identificar as áreas críticas à ocupação urbana situadas em superfícies consideradas de risco iminente à ocorrência de deslizamentos de terra na bacia hidrográfica do riacho Reginaldo. O estudo é parte do esforço empregado pelo Ministério Público de Alagoas em parceria com diversos órgãos públicos nas três esferas administrativas, no intuito de diagnosticar a realidade socioambiental da área estudada. Os resultados aqui apresentados são decorrentes de procedimentos realizados em sistemas geográficos de informação, e demonstram que apenas 5,95\% da extensão espacial analisada é classificada como área crítica à ocupação urbana com alto risco de deslizamento de terra. Geralmente, essas áreas estão associadas a uma ocupação de alta densidade populacional, com edificações de baixo padrão, típicas de aglomerados subnormais. A partir disso, o conhecimento dessas áreas pode contribuir para o planejamento urbano do território no município de Maceió.
\end{abstract}

Palavras-chave: Urbanização, encostas, geoprocessamento.

\section{CRITICAL AREAS FOR URBAN OCCUPATION SUSCEPTIBLE TO LANDSLIDING IN REGINALDO CREEK WATERSHED, MACEIÓ-AL}

\begin{abstract}
Human presence on the slopes of the coastal trails has been transforming this environment considerably, about to be vulnerable to natural factors, such as rainfall and the anthropic factors promoted by its influence, such as the discharge of open effluents. The objective of this study is to identify critical areas of urban occupation located on surfaces considered to be imminent to the occurrence of landslides in the Reginaldo river basin. The study is part of the effort employed by the Public Prosecutor of Alagoas in partnership with several public agencies in the three administrative spheres, in order to diagnose the social and environmental reality of the studied area. The results presented here are derived from procedures performed in geographic information systems, and show that only $5.95 \%$ of the spatial extent analyzed is classified as a critical area for urban occupation with high risk of landslide. Generally, these areas are associated with a high population density occupation, with low standard buildings, typical of subnormal clusters. From this, the knowledge of these areas can contribute to the urban planning of the territory in the municipality of Maceió.
\end{abstract}

Keywords: Urbanization; slopes; geoprocessing. 


\section{INTRODUÇÃO}

As encostas, enquanto ambiente dinâmico, estão sujeitas a transformações em sua forma e estrutura através de fatores naturais, os quais são apontados por Christofoletti (1974) como aqueles associados, principalmente, à estrutura das rochas e às variáveis climáticas; e de fatores antrópicos, conforme descrito por Santos et al (2014), pois a ação do homem, através de ocupação desordenada com lançamento de águas servidas diretamente nas encostas e da promoção de cortes de taludes, tem modificado significativamente essa feição geomorfológica.

Anjos (2004) corrobora com esse pensamento, ao afirmar que essa interação homem-meio, representada pela ocupação indisciplinada do solo em ambientes instáveis como as encostas, tem um alto poder de modificação da paisagem, muitas vezes superior aos agentes naturais, acelerando a dinâmica do intemperismo e da erosão.

A associação entre a ocupação de encostas, que ocorre de forma desordenada e frequentemente por estruturas precárias, e a intensidade pluviométrica de uma determinada região, tem transformado esses ambientes em zonas de risco à vida humana e ao patrimônio, uma vez que a ocorrência de movimentos de massa, nas cidades brasileiras que convivem com essa realidade, está sempre relacionada a episódios de chuvas (PARIZZI et al., 2010).

Nesse sentido, o entendimento de áreas críticas está intimamente associado ao conceito de risco ambiental pois este se apropria dos conceitos de suscetibilidade e vulnerabilidade na sua definição. Portanto, compreende-se que as áreas críticas são resultantes da probabilidade de acontecimentos de evento de natureza perigosa com estimativa de consequências danosas diretas e indiretas às pessoas e ao meio ambiente (ANDRADE, 2016).

Nesse contexto, admite-se que as áreas críticas são aquelas que representam as localizações mais vulneráveis a um determinado perigo, isto é, correspondem à sensibilidade desse lugar sofrer os efeitos diretos de impactos de eventos negativos provenientes de ações antrópicas ou naturais.

Numa perspectiva mais cartográfica, Xavier-da-Silva (2001) define áreas críticas como aquelas que correspondem ao confronto entre os planos de informação de uso da terra e de estimativas de riscos ambientais. Neste caso, tem-se como exemplo a integração do mapa de uso da terra e do mapa de risco a deslizamentos, resultando no mapa sinótico de áreas críticas de deslizamentos.

O confronto de cartogramas digitais ocorre através do emprego de técnicas de geoprocessamento, pois estas são uma tecnologia que representa o mundo real em meio computacional (CÂMARA; DAVIS; MONTEIRO, 2001) devido a sua visão integradora nos estudos ambientais.

O objetivo deste trabalho é identificar as possíveis áreas críticas à ocupação urbana situadas em áreas consideradas como de risco iminente à ocorrência de deslizamentos de terra na bacia hidrográfica do riacho Reginaldo, como parte integrante do plano estratégico (2011/2022) de recuperação ambiental desse recurso hídrico realizado pelo Ministério Público Estadual de Alagoas, contando ainda com a participação de diversos órgãos públicos.

\section{ÁREA DE ESTUDO}

A bacia hidrográfica do riacho Reginaldo localiza-se na porção sul do município de Maceió, possui forma estreita e alongada, orientando-se longitudinalmente por aproximadamente 11,75 km de extensão, com largura máxima de $2,77 \mathrm{~km}$; estando totalmente inserida na malha urbana dessa cidade (Figura 1).

Situa-se entre as coordenadas UTM no fuso 25L de longitudes $197.517,79 \mathrm{~m}$ E e 202.464,64 m E; e latitudes 8.929.749,56 m N e 8.940.811,55 m N. Computa uma área de aproximadamente $2.343,27$ hectares $\left(23,43 \mathrm{~km}^{2}\right)$, circunscrita em um perímetro de 31 quilômetros, abrangendo partes de 20 bairros, desde a sua nascente, no bairro de Santa Lúcia, até a foz, entre os bairros do Centro e Jaraguá. 
Figura1. Localização da área de estudo.

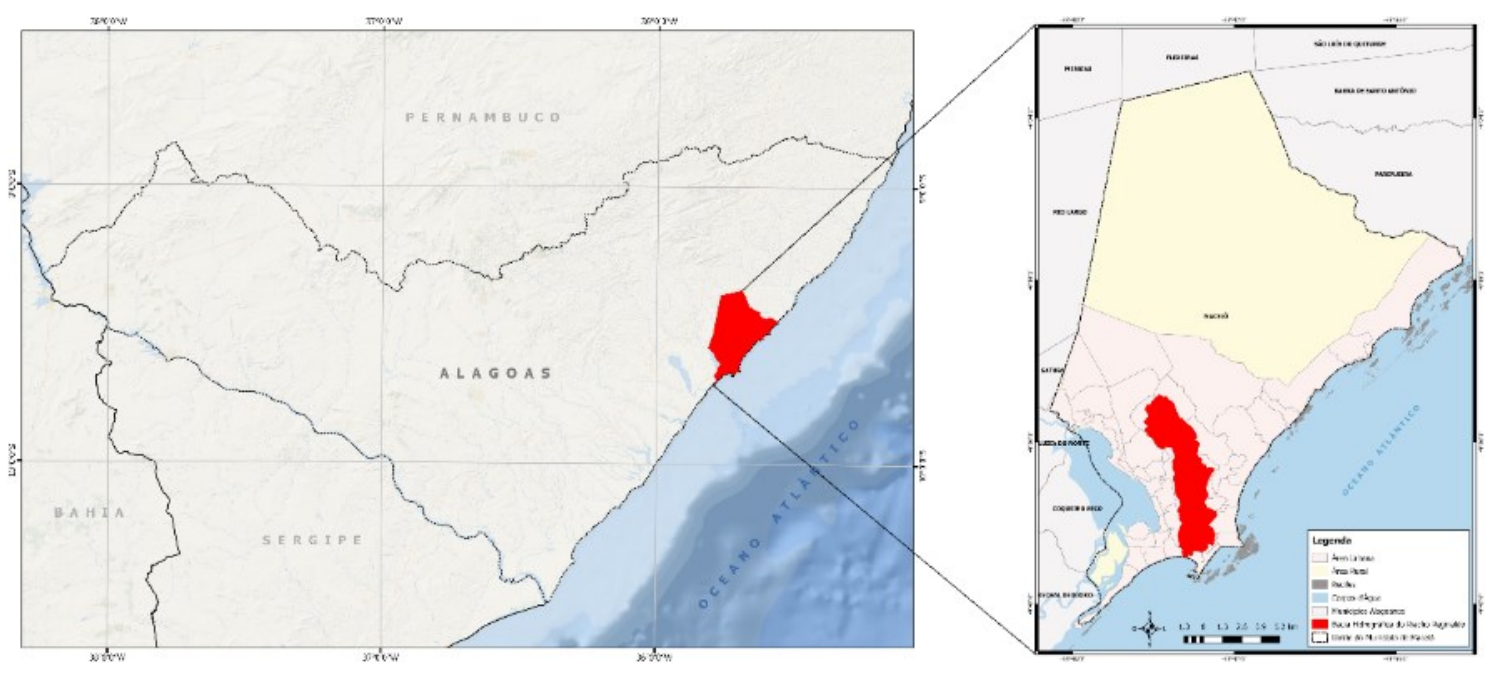

A área objeto está sob o domínio dos climas do tipo Úmido e Subúmido, segundo a classificação de Thornthwaite e Mather (1955), que se caracteriza, principalmente, pela irregularidade na distribuição anual das precipitações, propiciando um acumulado total anual de chuvas que varia entre $1.500 \mathrm{~mm}$ e $1.900 \mathrm{~mm}$ (EMBRAPA, 2012) e uma uniformidade térmica durante todo o ano, em que a temperatura média é de $26^{\circ} \mathrm{C}$, associada a um índice de umidade que varia de $20 \%$ a $60 \%$, resultando, assim, em excedente hídrico médio de 3 (três) a 6 (seis) meses, ao tempo em que a deficiência hídrica média varia de 4 (quatro) a 5 (cinco) meses (FONSECA; AZEVEDO, 1983; KISHI; CENTENO, 1992; ABREU, 1999). Em relação ao relevo, é constituída majoritariamente pelos Tabuleiros Costeiros (Formação Barreiras - ENb), compostos das formas de relevo Encostas de Vales Fluviais, Falésias Fósseis, Patamares Tabuliformes Aplanados e Dissecados, Rampas de Colúvio e Terraços Colúvio-Aluviais. É constituída ainda pela Planície Costeira, formada pelos Sedimentos de Praia e Aluvião (Qspa), representando as feições geomorfológicas Terraços Fluviomarinhos, Terraços Marinhos, Feixes de Cordões Praiais e Terraços Marinhos Coluviais.

As cotas altimétricas variam de zero metro ao nível médio do mar, no exutório desta bacia, atingindo 96 metros no seu limite norte. Nas cotas mais baixas, onde se situam o fundo dos vales, as planícies fluviais, os terraços aluviais e a planície litorânea, predominam os solos dos tipos Neossolos Flúvicos e Neossolos Quartzarênicos, respectivamente. Já nas cotas mais altas, compreendidas pelas encostas e superfícies planas, preponderam os Argissolos VermelhoAmarelos e os Latossolos Amarelo e Vermelho-Amarelo, respectivamente.

As terras são ocupadas por áreas edificadas em aproximadamente $77 \%$ da bacia, contando ainda com fragmentos remanescentes e descaracterizados de vegetação das fitofisionomias Cerrado, Floresta Ombrófila Secundária, Formações Pioneiras Fluviais e, minoritariamente, de vazios urbanos.

Em relação aos cursos d'água dispostos na bacia hidrográfica, pode-se afirmar que o riacho Reginaldo é um corpo hídrico com hierarquia de ordem 3, conforme classificação desenvolvida por Strahler (1952), contando com 140 canais de escoamento da nascente à foz. Essa quantidade totaliza uma extensão de 71,67 quilômetros de cursos d'água; o que resulta em uma densidade de $3,06 \mathrm{~km} / \mathrm{km}^{2}$, conferindo-lhe um status de alta densidade, de acordo com a classificação de Carvalho e Silva (2006), o que permite contabilizar 5,98 canais por $\mathrm{km}^{2}$. 
Calcula-se que a população residente em 2016, segundo estimativa da contagem da população realizada pelo IBGE, é de 306.513 pessoas. Isso corresponde a aproximadamente $30 \%$ da população do município.

Ao considerar essa contagem, admite-se uma densidade demográfica para a área total da bacia de $13.082 \mathrm{hab} . / \mathrm{km}^{2}$. Em comparação com os números do ano de 2010, referentes ao censo do IBGE, constata-se, portanto, um crescimento de $9,54 \%$, conferindo uma taxa de crescimento anual de $189,83 \mathrm{hab} . \mathrm{km}^{2}$.

Com base nisso, infere-se que há uma maior concentração demográfica nos bairros de Feitosa e Jacintinho, compreendendo o médio curso da bacia em questão. De acordo com Rodrigues et al. (2014) é nesta porção da área da bacia hidrográfica onde se situa a maior concentração de edificações de baixa qualidade que denotam a deficiência, ou até mesmo a ausência, de serviços públicos, estando tais construções em grande parte associadas a características socioeconômicas e geoambientais desfavoráveis; quase sempre sujeitas às consequências das condições extremas de precipitação pluviométrica.

\section{PROCEDIMENTOS METODOLÓGICOS}

A abordagem metodológica baseou-se na integração complexa de dados, que corresponde à combinação de mapas que usam integrações prévias como base para sua elaboração (XAVIERDA-SILVA, 2001, p. 178), objetivando identificar as áreas críticas à ocupação urbana na bacia hidrográfica em questão.

\section{Base de dados}

A base de dados utilizada neste trabalho, para o meio físico, integra o acervo digital do Laboratório de Geoprocessamento Aplicado do Instituto de Geografia, Desenvolvimento e Meio Ambiente da Universidade Federal de Alagoas (LGA-IGDEMA-UFAL), em escala de 1:50.000, com cartografia referente às cartas planialtimétricas do IBGE de 1985, correspondentes às folhas Maceió (SC-25-V-C-IV-2) e Pilar (SC-25-V-C-I-1) para os planos de informação de hipsometria, geomorfologia, pedologia, litologia e declividade. Para a pluviometria, adotou-se o acervo digital do zoneamento agroecológico de Alagoas elaborado pela Embrapa (2012); e para o uso do solo e cobertura vegetal, fez-se uso de imagens multiespectrais dos satélites Rapid Eye, com resolução espacial de 5 metros nas ortoimagens, sendo, portanto, compatível com a escala de 1:50.000.

\section{Integração dos dados}

A integração dos dados é aqui entendida como a conjugação das variáveis selecionadas mediante atribuição de pesos e notas, instruídas pelas planimetrias realizadas previamente para as classes pertencentes à base de dados e pelo conhecimento empírico da área estudada. Em analogia direta, corresponde à Avaliação Ambiental, concebida por Xavier-da-Silva (2001).

Devido a sua natureza integradora, o geoprocessamento dispõe de diversas técnicas de integração, sendo a álgebra de mapas a adotada neste estudo. Esta consiste na aplicação de operações aritméticas voltadas à associação de vários planos de informação (variáveis), de modo a obter como resultado classificações que permitem análises diversas. Assim, o emprego da análise multicritério pelo algoritmo da média ponderada permitiu agrupar e classificar áreas que contribuem na identificação das áreas de risco a deslizamentos de terra.

Os dados foram manipulados em formato vetorial Shapefile no ambiente QGIS 2.18, tendo como recorte espacial a delimitação da bacia hidrográfica do riacho Reginaldo, sendo posteriormente convertidos para o formato matricial GeoTIFF, através dos quais foram procedidas as integrações. 
Nas integrações realizadas através de média ponderada, os pesos são distribuídos de acordo com o grau de importância que cada mapa representa para o fenômeno estudado, até se atingir os $100 \%$ de responsabilidade na avaliação. As notas, por sua vez, são aplicadas segundo a possibilidade de associação das classes integrantes das variáveis selecionadas com a ocorrência do fenômeno em questão, e variam de 0 a 10 .

Assim, os pesos e notas foram atribuídos com base no conhecimento teórico e prévio da área de estudo, e também pelas observações e anotações de campo associados às planimetrias realizadas sobre cada tema, com vistas a equalizar os pesos e notas, a fim de se obter um produto verossímil junto à realidade.

Contudo, Calheiros (2000, p. 77) afirma que o algoritmo da média ponderada se dá pelo somatório do produto de pesos versus notas para cada célula (pixel) dos planos de informação submetidos à integração, de modo a resultar no mapa síntese para a finalidade desejada.

Mediante o exposto, definiu-se que as classes com uma participação nula no fenômeno em questão recebessem nota 0 (zero). As classes com participação quase nula e com pouquíssima participação receberam notas 1 (um) e 2 (dois), respectivamente. Já as classes com uma pequena participação receberam notas de 3 (três) e 4 (quatro). Já para aquelas com participação média, as notas variaram entre 5 (cinco) e 6 (seis), e aquelas com grande participação, entre 7 (sete) e 8 (oito). Nas classes em que as ocorrências eram muito possíveis e extremamente possíveis, foram atribuídas as notas 9 (nove) e 10 (dez), respectivamente.

\section{Integração dos dados para obtenção do mapa de riscos de deslizamento de terra}

Neste primeiro momento, foi realizada uma integração simples, ou seja, as variáveis foram combinadas de forma direta, isto é, sobre a base de dados original (ANDRADE, 2016, p. 112), decorrente da seguinte mecânica:

$$
\text { VariávelA }+ \text { VariávelB }+(\ldots)+\text { VariávelZ }=\text { MapaSintese } A
$$

Dessa forma, para a obtenção dos mapas potenciais de deslizamento de terra e de enchentes, foram combinadas as variáveis: Declividade, Solos, Geomorfologia, Pluviometria e Litologia, as quais receberam pesos e notas, conforme Quadro 1.

\section{Integração dos dados para obtenção do mapa de áreas críticas de deslizamento de Terra}

Para a geração do Mapa Síntese de Áreas Críticas, foram cruzados o plano de informação de Áreas de Riscos de Deslizamento e o plano de informação de Uso e Ocupação do Solo e Cobertura Vegetal.

Para se chegar ao mapa sinótico de áreas críticas, recorreu-se ao processamento por intermédio do algoritmo de união de camadas, o qual tem por regra a sobreposição de camadas de forma que a saída contenha a interseção e a não interseção de áreas.

Quadro 1. Atribuição de pesos e notas para as variáveis e respectivas classes utilizados na integração para obtenção do mapa potencial de riscos de deslizamento de terra.

\begin{tabular}{cccc}
\hline Variáveis & Pesos & Classes & Notas \\
\hline \multirow{2}{*}{ Declividade } & $25 \%$ & Plana $\left(0-5^{\circ}\right)$ & 0 \\
& & Plana a Moderadamente Ondulada $\left(5-10^{\circ}\right)$ & 1 \\
& & Moderadamente Ondulada a Ondulada $\left(10-15^{\circ}\right)$ & 3 \\
\hline
\end{tabular}




\begin{tabular}{|c|c|c|c|}
\hline & Ondulada $\left(15-20^{\circ}\right)$ & 4 \\
\hline & & Ondulada a Demasiadamente Ondulada $\left(20-25^{\circ}\right)$ & 5 \\
\hline & & Demasiad. Ondulada a Mod. Declivosa $\left(25-30^{\circ}\right)$ & 6 \\
\hline & & Moderadamente Declivosa a Declivosa $\left(30-35^{\circ}\right)$ & 7 \\
\hline & & Declivosa a Demasiad. Declivosa $\left(35-40^{\circ}\right)$ & 8 \\
\hline & & Demasiad. Declivosa a Escarpada $\left(40-45^{\circ}\right)$ & 9 \\
\hline & & Declividade Escarpada $\left(>45^{\circ}\right)$ & 10 \\
\hline \multirow{4}{*}{ Solos } & \multirow{4}{*}{$20 \%$} & Argissolos Vermelho-Amarelos & 10 \\
\hline & & Latossolos Amarelos e Vermelho-Amarelos & 3 \\
\hline & & Neossolos Flúvicos & 0 \\
\hline & & Neossolos Quartzarênicos & 0 \\
\hline \multirow{8}{*}{ Geomorfologia } & \multirow{8}{*}{$20 \%$} & Encostas de Vales Fluviais Tabuliformes & 10 \\
\hline & & Falésias Fósseis e Vales Fluviais Decapitados & 10 \\
\hline & & Patamares Tabuliformes Aplanados & 0 \\
\hline & & Rampas de Colúvio & 3 \\
\hline & & Terraços Colúvio-Aluvionares & 1 \\
\hline & & Terraços Marinhos Coluvionares & 1 \\
\hline & & Terraços Marinhos e Feixes de Cordões Praiais & 0 \\
\hline & & Topos Tabuliformes Dissecados & 1 \\
\hline \multirow{2}{*}{ Pluviometria } & \multirow{2}{*}{$15 \%$} & $92-125 \mathrm{~mm} / \mathrm{mês}$ & 6 \\
\hline & & $125-158 \mathrm{~mm} / \mathrm{mês}$ & 7 \\
\hline \multirow{2}{*}{ Litologia } & \multirow{2}{*}{$10 \%$} & Formação Barreiras (Tb) & 10 \\
\hline & & Sedimentos de Praia e Aluvião (Qspa) & 0 \\
\hline
\end{tabular}

\section{RESULTADOS E DISCUSSÃO}

Os resultados aqui apresentados dizem respeito às áreas críticas sujeitas a deslizamento de terra associados à ocupação urbana (Figura 2). As classes de uso do solo identificadas no respectivo mapeamento dizem respeito às Áreas Edificadas, aos Fragmentos de Vegetação e aos Vazios Urbanos.

Foram consideradas nesta análise como áreas críticas apenas aquelas as quais resultaram de cruzamento das classes do plano de informação de Risco de Deslizamento e a classe de Áreas Edificadas, referente ao cartograma de Uso do Solo. As classes Fragmentos de Vegetação e Vazios Urbanos, que correspondem a $23 \%$ da área em questão, foram excluídas da análise, pois não atendem ao critério de ocupação urbana consolidada através de edificações.

Diante disso, a planimetria efetuada sobre o mapa sinótico das áreas críticas revelou que aproximadamente $77 \%$ da área analisada apresenta áreas críticas a algum grau de risco de deslizamento.

Deste percentual, destaca-se a classe Áreas Críticas à Ocupação Urbana com Baixo Risco de Deslizamento, com a maior taxa de ocupação: $50,26 \%$ da bacia hidrográfica. (Tabela 1). 
Figura2. Áreas críticas à ocupação urbana mediante riscos de deslizamento.

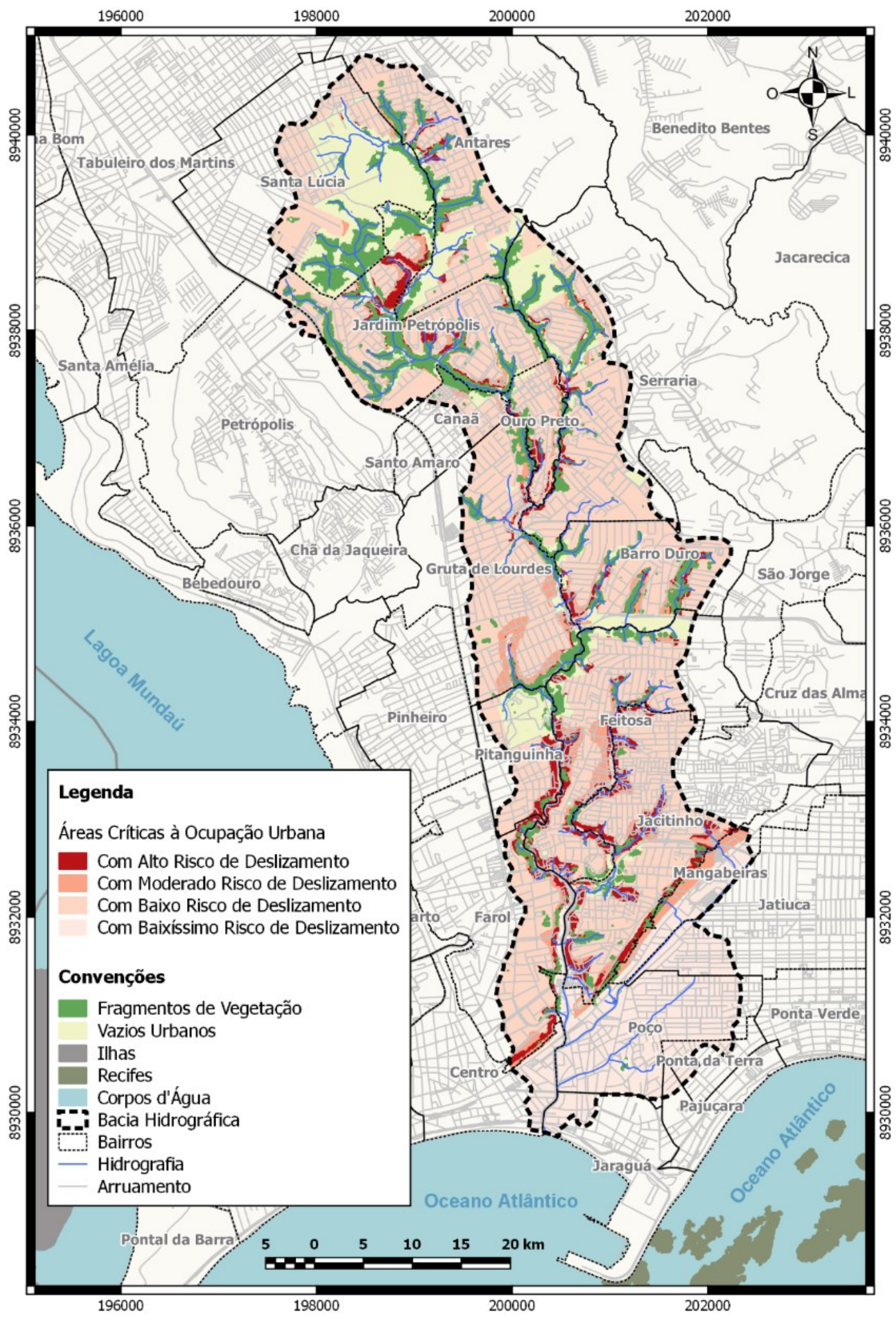


Tabela 1. Distribuição percentual das classes de áreas críticas ao risco de deslizamento de terra.

\begin{tabular}{|c|c|c|}
\hline Classes & $\begin{array}{c}\text { Área } \\
\text { (ha) }\end{array}$ & $\%$ \\
\hline Áreas críticas à ocup. urb. com alto risco de deslizamento & 139,36 & 5,95 \\
\hline Áreas críticas à ocup. urb. com moderado risco de deslizamento & 180,16 & 7,69 \\
\hline Áreas críticas à ocup. urb. com baixo risco de deslizamento & $1.177,74$ & 50,26 \\
\hline Áreas críticas à ocup. urb. com baixíssimo risco de deslizamento & 310,77 & 13,26 \\
\hline Fragmentos de vegetação & 280,91 & 11,99 \\
\hline Vazios urbanos & 254,33 & 10,85 \\
\hline Totais & $2.343,27$ & 100,00 \\
\hline
\end{tabular}

\section{Áreas críticas à ocupação urbana com alto risco de deslizamento}

Ocupam uma área de 139,36 hectares, o que corresponde a 5,95\% de toda área analisada. Estendem-se por estreita faixa nas Encostas de Vales Fluviais ao longo de quase todo o canal do riacho Reginaldo e em alguns afluentes paralelos ao curso principal. Estendem-se ainda nos flancos que limitam os ambientes terciários e os separa dos quaternários, correspondendo às Falésias Fósseis, abrangendo localidades como a sede do Conselho Regional de Engenharia e Agronomia, TV Ponta Verde, Indústria Sococo e Supermercado Extra.

Nessas áreas, o gradiente topográfico varia de $25^{\circ}$ a maiores que $45^{\circ}$, conferindo declividades que vão de onduladas a escarpadas. Ocorrem majoritariamente nas faixas altimétricas que variam de 30 a 70 metros em relação ao nível médio do mar. Devido a sua natureza de risco a deslizamentos de terra, são consideradas áreas legalmente restritas ao uso e ocupação do solo, em conformidade com o Art. 146, inciso III da Lei municipal $\mathrm{n}^{\circ}$. 5.593/2007, que dispõe sobre o parcelamento do solo urbano no município de Maceió; e do Art. $4^{\circ}$, inciso V da Lei federal n ${ }^{\circ} .12 .651 / 2012$, que trata da delimitação das Áreas de Preservação Permanente.

Abrangem o solo do tipo Argissolo Vermelho-Amarelo que, devido as suas propriedades físicoquímicas, é muito suscetível à erosão, sendo, portanto, não recomendável à ocupação urbana.

São em ambientes com essas características geoambientais onde estão estabelecidos 23 dos 24 aglomerados subnormais existentes na bacia hidrográfica. São áreas que possuem, predominantemente, uma densidade demográfica que varia de 200 a 1.500 hab./ha. Cerca de $70 \%$ da classe em questão abrange setores censitários onde a renda média é de até 1,2 salário mínimo e a população residente tem em média até 7 (sete) anos de estudo, ou seja, a escolaridade máxima da maioria é o quinto ano do ensino fundamental.

Diante disso, entende-se que as áreas de encostas, com declividade superior a 30 graus, não devem ser ocupadas. No entanto, a realidade se contrapõe às legislações, pois essa forma de relevo é ocupada, majoritariamente, por edificações de baixa qualidade. Assim, sugere-se que o poder público incentive políticas que oportunizem alternativas tecnológicas estruturais, amparando a ocupação urbana dessas superfícies.

\section{Áreas críticas à ocupação urbana com moderado risco de deslizamento}

Esta classe envolve uma área de 180,16 hectares, representando 7,69\% da bacia hidrográfica em questão. Prolonga-se pelo terço superior das Encostas de Vales Fluviais e bordas dos Patamares Tabuliformes Aplanados. Correspondem a áreas predominantemente com declividades baixas, variando de plana $\left(0^{\circ}-5^{\circ}\right)$ a ondulada $\left(15^{\circ}-20^{\circ}\right)$, compreendidas em altitudes de 50 a 80 metros.

Compreendem os solos Argissolos Vermelho-Amarelos, suscetíveis à erosão devido a sua composição predominantemente de argila. Envolvem também os Latossolos Amarelos, pouco 
suscetíveis aos processos erosivos, pois possuem boas propriedades físicas, como a permeabilidade à água e ao ar, e mesmo com alta porcentagem de argila; são porosos, friáveis, de baixa plasticidade. Abarcam ainda os Latossolos Vermelho-Amarelos, que apresentam problemas físicos com limitações quanto à permeabilidade restrita, ou seja, elevada coesão dos agregados, pois é extremamente duro quando seco, e a infiltração de água é lenta.

Sobre essas áreas assentam-se, preponderantemente, uma população com densidade variante entre 0 (zero) e 150 hab./ha, na qual a renda média de aproximadamente $60 \%$ das famílias é de até 1,2 salários mínimos; e outros $20 \%$, variam de 1,2 a 2,5 salários mínimos. A escolaridade média verificada dos residentes situados nesta classe de áreas críticas concentra-se entre o sexto ano do ensino fundamental e o terceiro ano do ensino médio, isto é, corresponde ao intervalo de 7 e 12 anos de estudo.

Perante o exposto, recomenda-se ao poder público a implementação de obras de proteção do solo quanto aos efeitos das chuvas, integrado a um sistema de drenagem pluvial que não prejudique a recarga dos aquíferos, baseados em valas de infiltração ou sumidouros, a depender de estudos geotécnicos.

\section{Áreas críticas à ocupação urbana com baixo risco de deslizamento}

Esta categoria detém a maior expressão areal da área de estudo. São 1.177,74 hectares, ou seja, $50,26 \%$ da manifestação espacial do fenômeno em questão. Compreende toda a parte alta da bacia hidrográfica, representada pelas unidades geomorfológicas Patamares Tabuliformes Aplanados, situados nas porções centro-norte e centro-oeste da bacia; Topos Tabuliformes Dissecados, dispostos na porção centro-leste da mesma área e em partes dos Terraços Colúvio-Aluvionares.

Todas essas áreas são compostas de declividade plana a moderadamente ondulada, nas quais os gradientes topográficos vão de $0^{\circ}$ a $5^{\circ}$ e de $5^{\circ}$ a $10^{\circ}$, respectivamente, prevalecendo sobre os terrenos com faixas altimétricas compreendidas entre 40 e 50 metros em relação ao nível médio do mar; onde os solos Latossolos Amarelos e Vermelho-Amarelos compõem a paisagem mais alta. Em relação aos ambientes mais baixos, os solos identificados são os Neossolos Flúvicos dispostos nos sopés dos Terraços Colúvio-Aluvionares.

Os deslizamentos são pouco prováveis nessas áreas, sendo possíveis somente em situações sob o domínio de fortes intensidades pluviométricas, causando desagregação da estrutura física dos solos, mesmo com topografia plana a moderadamente ondulada.

Estão associadas a essas áreas, majoritariamente, faixas de densidades demográficas que vão de 0 a 50 hab./ha até 100 a 150 hab./ha. Em relação à distribuição de renda, aproximadamente $30 \%$ da classe analisada situa-se sob setores censitários nos quais as famílias percebem até 1 (um) salário mínimo, estando esse fator associado a uma escolaridade de até 7 (sete) anos nesse grupo; cerca de $25 \%$ estão sob setores nos quais a renda varia entre 2,5 a 4,3 salários mínimos, relacionando-se com residentes que possuem de 7 a 12 anos de estudo; outros $25 \%$ ganham entre 4,3 e 7 salários mínimos e possuem ensino superior completo, ou seja, têm até 15 anos de estudo.

\section{Áreas críticas à ocupação urbana com baixíssimo risco de deslizamento}

Computam uma área de 310,77 hectares, o que corresponde a 13,26\% de toda extensão analisada. Estendem-se basicamente sobre os Sedimentos Quaternários de Praia e Aluvião, os quais comportam as unidades geomorfológicas dos Terraços Marinhos, Feixes de Cordões Praiais e o fundo dos vales, correspondente aos Terraços Colúvio-Aluvionares.

Nessas áreas, o gradiente topográfico varia de $0^{\circ}$ a $5^{\circ}$, conferindo uma declividade totalmente plana, sob altitudes de até 10 metros; e, ao contrário do fenômeno analisado, são áreas sujeitas a alagamentos. 
Os solos presentes nesta categoria de áreas críticas são os Neossolos Quartzarênicos sobre os Terraços Marinhos e os Neossolos Flúvicos sobre os Terraços Colúvio-Aluvionares. Os primeiros se caracterizam por apresentar uma textura arenosa altamente permeável ao longo de pelo menos $2 \mathrm{~m}$ de profundidade. Já os segundos solos possuem uma granulometria bastante diversificada em seu perfil, devido a sua formação ter sido mediante a sobreposição de camadas de sedimentos de origem aluvial.

São em ambientes com essas características físicas onde se estabelece predominantemente uma população com densidade de até 200 hab./ha. Aproximadamente $70 \%$ da classe em questão abrange setores censitários onde a renda varia de 1,2 salário mínimo a 2,5 salários mínimos e a população residente possui de 7 a 12 anos de estudo, ou seja, a escolaridade mínima corresponde ao sexto ano do ensino fundamental e a máxima diz respeito ao terceiro ano do ensino médio.

\section{CONCLUSÕES}

Diante do que foi apresentado, é possível afirmar que as áreas edificadas nas zonas de alto risco a deslizamento de encostas na área da bacia hidrográfica estão, quase sempre, em situação de vulnerabilidade socioambiental, pois não existe planejamento ordenado de ocupação urbana, potencializando, assim, os danos e perdas quando da ocorrência de catástrofes. Dessa forma, visando à antecipação de acidentes dessa natureza, faz-se necessária a adoção de iniciativas públicas de prevenção, contenção e mitigação da ocupação desordenada.

As análises espaciais realizadas por meio do geoprocessamento possibilitaram a identificação das áreas com graus diferentes de criticidade à ocupação urbana, suscetíveis ou não de riscos de movimentos de massa; demonstrando que a metodologia adotada atendeu ao propósito, atestando sua adequação e facilidade de utilização, o que permite sua reprodução e universalização.

Finalmente, o conhecimento da localização das áreas críticas, apoiado em dados disponibilizados em meios públicos, pode contribuir para o planejamento urbano do território no município de Maceió, ao fornecerem informações relevantes de apoio à tomada de decisão por parte dos entes públicos.

\section{REFERÊNCIAS}

ABREU, R. de A. Relatório da análise climática do estado de Alagoas. Maceió: Governo de Alagoas, Núcleo de Meteorologia e Recursos Hídricos, 1999. 31 f. Mimeografado.

ANDRADE, E. de L. Áreas de risco ambiental aos acidentes com transporte rodoviário de produtos perigosos no trecho alagoano da rodovia BR-101: uma proposta metodológica. 2016. 192 f. Dissertação (Mestrado) - Curso de Geografia, Instituto de Geografia, Desenvolvimento e Meio Ambiente, Universidade Federal de Alagoas, Maceió, 2016. Disponível em: <https://goo.gl/SP1KBB>. Acesso em: 03 mar. 2017.

ANJOS, C. A. M. dos. Ocupação de encostas urbanas: uma dicotomia sócio-ambiental. In: ARAUJO, L. M. de. Geografia: espaço, tempo e planejamento. Maceió: Edufal, 2004. p. 207-230.

CALHEIROS, S. Q. C. Turismo versus agricultura no litoral meridional de Alagoas. Rio de Janeiro: UFRJ. 2000. v.1 e 2. Tese (Doutorado em Geografia - Centro de Ciência Exatas e da Natureza) Universidade Federal do Rio de Janeiro, Rio de Janeiro.

CÂMARA, G.; DAVIS, C.; MONTEIRO, A. M. V. (Org.). Introdução à ciência da geoinformação. São José dos Campos: Inpe, 2001. 346 p. Disponível em: <http://goo.gl/oymLaC>. Acesso em: 25 mai. 2017.

CARVALHO, D. F. de; SILVA, L. D. B. da. Hidrologia. Seropédica: Particular, 2006. Disponível em: $<$ http://goo.gl/ASCYKU>. Acesso em: 21 set. 2015. 
CHRISTOFOLETTI, A. Geomorfologia. São Paulo: Edgard Blucher Ltda/EDUSP. 1974. 130 p.

EMPRESA BRASILEIRA DE PESQUISA AGROPECUÁRIA - EMBRAPA. Centro Nacional de Pesquisa de Solos. Unidade de Execução de Pesquisa e Desenvolvimento em Recife. Mapa pluviométrico do estado de Alagoas. In: Zoneamento agroecológico de Alagoas. Recife: Convênio SEAGRI-AL, EMBRAPA, Solos, $\mathrm{n}^{\mathrm{o}}$ 10200.09/0134-5. 2012.

FONSECA, A. L. B. de AZEVEDO, L. M. P. Climatologia. In: BRASIL, MINISTÉRIO DAS MINAS E ENERGIA SECRETARIA GERAL, PROJETO RADAMBRASIL. Folhas SC.

KISH, R. T.; CENTENO, J. A. S. Avaliação da Rede de Coleta de Dados Pluviométricos no estado de Alagoas. I Simpósio de Recursos Hídricos do Nordeste, Recife-PE, p.211-215, 1992.

PARIZZI, M. G. et al. Correlações entre chuvas e movimentos de massa no município de Belo Horizonte, MG. Geografias, Belo Horizonte, v. 2, n. 6, p.49-68, jul. 2010. Semestral. Disponível em: $<$ https://goo.gl/nGPkRe>. Acesso em: 04 jun. 2017.

RODRIGUES, B. T. et al. Delimitação de bacias hidrográficas e áreas de contribuição formadoras de esgoto e variáveis socioeconômicas utilizando técnicas de geoprocessamento. In: XXVI CONGRESSO BRASILEIRO DE CARTOGRAFIA E V CONGRESSO BRASILEIRO DE GEOPROCESSAMENTO, 26. 2014, Gramado. Anais... . Rio de Janeiro: SBC, 2014. p. 1 - 10. Disponível em: $<$ https://goo.gl/vsvaf3>. Acesso em: 23 fev. 2017.

SANTOS, J. R. U. dos et al. Os impactos antropogênicos versus riscos geomorfológicos em encostas urbanas: um estudo de caso no bairro de Bebedouro, Maceió - Alagoas. In: SIMPÓSIO NACIONAL DE GEOMORFOLOGIA, 10., 2014, Manaus. Anais... . Manaus: Sinageo, 2014. p. 1 - 5. Disponível em: $<$ https://goo.gl/p3NvSk>. Acesso em: 01 mar. 2017.

STRAHLER, A. N. Hypsometric (area-altitude) analysis of erosional topology. Geological Society of America Bulletin. 63 (11): 1117-1142. 1952

THORNTHWAITE, C. W.; MATHER, J. R. The water balance. Publication in Climatology, Laboratory of Climatology, Centerton, v. 8, n.1. 1955.

XAVIER DA SILVA, J. Geoprocessamento para análise ambiental. Rio de Janeiro: J. Xavier da Silva, 2001. 228p. 